\title{
Association between self-management behaviour and quality of life in people with heart failure: a retrospective study
}

\author{
Eui-Young Choi ${ }^{1 \dagger}$, Jin-Sun Park ${ }^{2 \dagger}$, Deulle Min ${ }^{3}$, Hye Sun Lee ${ }^{4}$ and Jeong-Ah Ahn ${ }^{5^{*}}$ (1)
}

\begin{abstract}
Background: The purpose of this study was to investigate the variables that significantly associated with the quality of life in people with heart failure, and particularly, to identify the association between self-management behaviour and the quality of life.

Methods: This retrospective study used data from heart failure outpatient clinics at two large tertiary medical centres in Seoul and Suwon, South Korea. We enrolled 119 participants who completed echocardiography and stress tests and responded to questionnaires on self-management behaviour and quality of life. We collected more data on sociodemographic and clinical characteristics and anthropometric and serum blood test results through electronic medical record review. We analysed data using multiple linear regression and the classification and regression tree (CART) method to explore the associated factors with the quality of life in participants with heart failure.
\end{abstract}

Results: Participants' mean age was 74.61 years, and women represented $52.1 \%$ of the sample. It showed that cardiac systolic function ( $\beta=0.26, p=.013)$ and self-management behaviour $(\beta=0.20, p=.048)$ were two major associated factors with the quality of life in participants with heart failure in the multiple linear regression analysis. Also, cardiac systolic function and self-management behaviour were shown to be the primary determinants for the quality of life in those with heart failure in the CART analysis. Therefore, self-management behaviour of the participants with heart failure was a significant modifiable factor that can improve their quality of life.

Conclusions: Healthcare providers should be aware of the importance of self-management in people with heart failure and help promote their quality of life by enhancing their self-management behaviour as own efforts to properly maintain and monitor the health status and prevent further worsening of heart failure.

Keywords: Self-management, Quality of life, Heart failure, Prediction model

\section{Background}

Heart failure (HF) is a heterogeneous series of clinical syndromes associated with a poor prognosis, in which the body is unable to supply the proper amount of blood

\footnotetext{
*Correspondence: ahnj@ajou.ac.kr

†Eui-Young Choi and Jin-Sun Park have contributed equally to this work

${ }^{5}$ College of Nursing and Research Institute of Nursing Science, Ajou

University, Worldcup-ro 164, Yeongtong-gu, Suwon 16499, Republic

of Korea

Full list of author information is available at the end of the article
}

for metabolism due to decreased heart function [1]. According to 2013-2016 data from the National Health and Nutrition Examination Survey in the United States, the prevalence of HF continues to rise over time; it was estimated to be approximately 6.2 million, compared with an estimated 5.7 million between 2009 and 2012 [2]. This phenomenon has become a global problem with the increased aging population, and hospitalization due to HF is the leading cause of overall hospitalization in the United States and European countries [3, 4]. HF cannot 
be completely cured and requires lifelong management. Repeated hospitalizations for HF affect the health care system, resulting in a high social and economic burden [3]. A systematic review of 16 studies (between 2004 and 2016) analysed the cost associated with HF and reported that the annual medical expenses ranged from $\$ 868$ to $\$ 25,532$, with the lifetime cost for a person with HF estimated at $\$ 126,819$ [5].

People with HF can be divided into four classes using the New York Heart Association (NYHA) classification based on the severity of symptoms and related physical effort needed [6]. They can also be divided into stages A (high risk of developing HF in the future) to D (advanced HF) [7]. The assessment for HF classification should consider not only a careful clinical evaluation but also the individual's psychosocial factors, for instance, the quality of life (QoL), which can be a more important factor outside the hospital management [8]. People with HF usually suffer from a variety of physical symptoms such as dyspnea, dizziness, edema, lack of energy, and sleep disturbance, and psychological problems such as stress, anxiety, and depression along with changes in heart function, further reducing overall QoL [9]. The treatment goal for HF is to control the worsening symptoms, reduce rehospitalizations, and maintain survival [10]. Accordingly, individual self-management plays an important role in HF management. Self-management is defined as a process of maintaining health status through individual's health promoting and preventive practices [11]. For people with HF, self-management includes three key aspects of maintenance (i.e., taking medication as prescribed, engaging in physical activity, and adhering to a therapeutic diet), monitoring (i.e., regular weighing to check for body fluid accumulation and watching for symptoms of worsening), and management (i.e., controlling water or salt intake and changing medication dose in response to symptoms) [10]. People with HF need to recognise their exacerbating signs and manage related factors, and through this, they will be able to improve their QoL and lower their mortality. Thus, self-management is a necessary focus in life-long HF care, which people with HF should continue throughout their lives [10, 11], while healthcare providers should ensure the best possible QoL in those with HF [12].

Recently, many studies on self-management and QoL in people with HF have been conducted. However, according to a systematic review of 30 studies, there was a discrepancy among the individual study results, which examined the relationship between health-related QoL and self-management in those with HF [13]. The discrepancy also appeared in interventional studies. One systematic review of 19 randomised controlled trials reported that some self-management interventions significantly affected the QoL of participants with HF, but others did not [14]. As such, many studies have emphasised the importance of self-management and QoL in people with HF; however, their results have been inconsistent. The purpose of this study was to consider various possible factors associated with the QoL in participants with HF, and particularly, to investigate the association between self-management behaviour and the QoL.

\section{Methods}

\section{Study design and participants}

This study used a retrospective observational design. Participants for the present study were adults with HF who visited the outpatient departments of two large tertiary medical centres operating HF outpatient clinics in two cities of metropolitan area (Seoul and Suwon city), South Korea, for regular medical follow-ups between July 2017 and August 2019. We selected 119 participants who had performed relevant serum blood tests, echocardiography, and stress tests and responded to the surveys about self-management behaviour and the QoL on the same day. We collected their data retrospectively by electronic medical record review.

\section{Study variables}

Self-management behaviour was measured using the European Heart Failure Scale [15], a 12-item questionnaire related to self-care behaviour in HF. It includes the questions of consulting behaviours (i.e., "How often do you call your doctor/nurse in case of shortness of breath, ankle swelling, weight gain, or fatigue?") and adherence with the regimen (i.e., "How often do you weigh yourself, try to drink less water, follow a low-sodium diet, regularly take medication, or exercise?"). Also, their QoL was assessed using a measuring tool provided by the World Health Organization (WHOQOL-BREF) [16], a 26-item questionnaire on the individual's perceptions of their health and well-being. The participants' stress levels were measured using the heart rate variability (HRV) measurement tool of uBioMacpa (Biosense Creative, Seoul, Korea), which displays stress level on a scale of 0 to 100.

All participants underwent a comprehensive transthoracic echocardiographic evaluation, a standard 2-dimensional and Doppler echocardiographic examination, according to the recommendations of the American Society of Echocardiography [17]. Left ventricular systolic function was defined using the left ventricular ejection fraction (EF), calculated according to the modified Simpson's method (i.e., subtracting left ventricular end-systolic dimension from left ventricular end-diastolic dimension). Left ventricular diastolic function was defined as the early mitral inflow velocity to early diastolic mitral septal annular velocity (E/E'), calculated using 
pulsed-wave Doppler and tissue Doppler echocardiography. The evaluation was conducted using GE Vivid 7 (GE Healthcare, Horten, Norway) or iE33 (Philips Medical Systems, Andover, MA, USA), performed by 6 sonographers and 2 echocardiologists in one medical centre. In the other medical centre, it was conducted using Vivid E95 (GE Healthcare, Horten, Norway) or EPIQ CVX (Philips Medical Systems, Andover, MA, USA), which was performed by 8 sonographers and 2 echocardiologists. In this study, we only collected EF for cardiac systolic function and E/E' for cardiac diastolic function from the participants' echocardiographic results.

Electronic medical record review was performed to collect the participants' sociodemographic and clinical characteristics, anthropometric data, and serum blood test results, including hemoglobin $\mathrm{A} 1 \mathrm{C}$ (HbA1C), high-density lipoprotein (HDL), low-density lipoprotein (LDL), total cholesterol, triglyceride, and high sensitivity $\mathrm{C}$-reactive protein (hs-CRP).

\section{Statistical analyses}

Data were analysed using SPSS version 25.0 (IBM Corporation, Armonk, NY, USA).

Descriptive statistics (frequencies, percentages, means, and standard deviations) were used to explain the participants' sociodemographic and clinical characteristics, levels of stress, self-management behaviour, and QoL. Independent samples $t$-tests and $\chi^{2}$ tests were conducted to identify the differences in the variables according to the levels of low and high QoL. The two QoL levels were created by using a median split for the QoL measure.

Multiple linear regression analysis was performed to examine the relationships among QoL, EF, E/E', and selfmanagement behaviour. The choice of these variables for the regression analysis was based on the significance in the univariate analysis to identify the major factors that predict the QoL.

Lastly, the predictive model for QoL of participants was developed using decision tree analysis. Decision tree analysis is a data-mining technique designed to partition the whole dataset into subgroups based on splitting criteria [18]. We used the classification and regression tree (CART) method [18], which presents a hierarchical model structured as a tree for predicting the QoL of the participants. The tree model structure is made up of root nodes, splitting nodes (parent nodes), and terminal nodes (child nodes). Firstly, the dataset was partitioned into two subsets based on a predictor variable with the score of QoL. The process was repeated on each derived subset in an iterative (recursive partitioning) manner. This method looks for subgroups in the dataset in which the predictor variable is relatively homogeneous. At each node, the recursive partitioning identifies a predictor variable and a split by which may be subclassified [19].

\section{Results}

The mean age of the participants was 74.61 years, and $52.1 \%$ were women. The differences in the variables according to the groups with low and high QoL are presented in Table 1 . There were statistically significant differences in $\mathrm{EF}(p<0.001), \mathrm{E} / \mathrm{E}^{\prime}(p=0.045)$, and selfmanagement behaviour $(p<0.022)$ between low and high QoL groups. Participants with high QoL showed significantly higher EF, lower E/E', and better self-management behaviour scores than those with low QoL. No other statistically significant differences between the groups were observed.

The factors that significantly associated with the participants' QoL are shown in Table 2. Multiple linear regression analysis was performed with $\mathrm{EF}, \mathrm{E} / \mathrm{E}$, and self-management behaviour as the independent variables based on their significance in the univariate analysis to identify the major factors that predict the QoL. The regression model for the participants' QoL was shown to be significant $(p=0.003)$. The value of the adjusted $R^{2}$ was 0.11 , corresponding to the explanatory power of $11.0 \%$ for QoL. The major factors associated with the QoL were EF $(\beta=0.26, p=0.013)$ and self-management behaviour $(\beta=0.20, p=0.048)$.

To perform the CART analysis, we selected EF and self-management behaviour as the candidate predictors based on the regression analysis. The prediction model by CART analysis for the participants' QoL is shown in Table 3 and Fig. 1. The EF (cut-off value: 36\%) was shown to be the primary determinant of the participants' QoL. The lowest QoL group (Node 1; predictive QoL value of 3.08 out of 5) with 6 participants (5.0\%) had $\mathrm{EF} \leq 36 \%$, and their self-management score was lower than 3.29 out of 5. Contrarily, the highest QoL group (Node 5; predictive QoL value of 4.02) with 25 participants (21.0\%) had $\mathrm{EF}>69 \%$. In the group with $\mathrm{EF} \leq 36 \%$, if the participants' self-management score was higher than 3.29 (15 participants, $12.6 \%$ ), they showed a predictive QoL value of 3.24 (Node 2). The group, which had EF between 37 and $69 \%$, was divided into two nodes (Nodes 3 and 4). Node 3 (predictive QoL value of 3.66) included participants with self-management behaviour score $\leq 4.04$ (63 participants, 52.9\%), and Node 4 (predictive QoL value of 4.09) included participants with self-management behaviour score $>4.04$ (10 participants, $8.4 \%$ ).

\section{Discussion}

This study attempted to explore the factors associated with the QoL in people with HF and the importance of self-management on their QoL. Among the participants' 
Table 1 Participants' sociodemographic and clinical characteristics $(N=119)$

\begin{tabular}{|c|c|c|c|}
\hline Characteristics & $\begin{array}{l}\text { Low QoL }(n=59) \\
n(\%) \text { or mean } \pm \text { SD }\end{array}$ & High QoL $(n=60)$ & $p$ \\
\hline Age (range: 35-96) & $74.98 \pm 10.87$ & $74.23 \pm 11.75$ & .719 \\
\hline$<60$ & $4(6.8)$ & $7(11.7)$ & .651 \\
\hline $60-69$ & $13(22.0)$ & $9(15.0)$ & \\
\hline $70-79$ & $19(32.2)$ & $21(35.0)$ & \\
\hline$\geq 80$ & $23(39.0)$ & $23(38.3)$ & \\
\hline Spouse* & & & .476 \\
\hline Yes & $35(60.3)$ & $40(66.7)$ & \\
\hline No & $23(39.7)$ & $20(33.3)$ & \\
\hline Educational level* & & & .492 \\
\hline$\leq$ Middle school & $32(56.1)$ & $33(55.0)$ & \\
\hline$\leq$ High school & $17(29.8)$ & $14(23.3)$ & \\
\hline$\geq$ College/university & $8(14.0)$ & $13(21.7)$ & \\
\hline Occupation* & & & .562 \\
\hline Yes & $11(19.0)$ & $14(23.3)$ & \\
\hline No & $47(81.0)$ & $46(76.7)$ & \\
\hline Family history* & & & .416 \\
\hline Yes & $9(15.8)$ & $13(21.7)$ & \\
\hline No & $48(84.2)$ & $47(78.3)$ & \\
\hline Body mass index $\left(\mathrm{kg} / \mathrm{m}^{2}\right)$ & $24.45 \pm 4.29$ & $24.69 \pm 3.11$ & .733 \\
\hline Waist circumference (cm) & $88.54 \pm 10.10$ & $88.29 \pm 10.06$ & .919 \\
\hline Heart failure duration (y) & $7.23 \pm 4.87$ & $8.62 \pm 5.57$ & .155 \\
\hline Number of hospitalization & $1.28 \pm 0.97$ & $1.08 \pm 0.88$ & .286 \\
\hline \multicolumn{4}{|l|}{ Treatment* } \\
\hline Medication & & & .981 \\
\hline Yes & $57(98.3)$ & $59(98.3)$ & \\
\hline No & $1(1.7)$ & $1(1.7)$ & \\
\hline Internal Intervention & & & .115 \\
\hline Yes & $19(32.8)$ & $12(20.0)$ & \\
\hline No & $39(67.2)$ & $48(80.0)$ & \\
\hline Surgery & & & .411 \\
\hline Yes & $10(17.2)$ & $14(23.3)$ & \\
\hline No & $48(82.8)$ & $46(76.7)$ & \\
\hline NYHA class* & & & .222 \\
\hline 1 & $9(17.6)$ & $15(25.4)$ & \\
\hline$\|$ & $23(45.1)$ & $30(50.8)$ & \\
\hline III & $15(29.4)$ & $8(13.6)$ & \\
\hline IV & $4(7.8)$ & $6(10.2)$ & \\
\hline Systolic blood pressure (mmHg) & $121.51 \pm 17.77$ & $127.33 \pm 14.37$ & .501 \\
\hline Diastolic blood pressure $(\mathrm{mmHg})$ & $68.93 \pm 11.84$ & $73.07 \pm 13.52$ & .079 \\
\hline HbA1c (\%) & $6.64 \pm 1.10$ & $6.88 \pm 1.10$ & .517 \\
\hline $\mathrm{HDL}(\mathrm{mg} / \mathrm{dL})$ & $49.47 \pm 15.06$ & $46.77 \pm 11.95$ & .319 \\
\hline $\mathrm{LDL}(\mathrm{mg} / \mathrm{dL})$ & $85.76 \pm 37.36$ & $85.13 \pm 30.38$ & .926 \\
\hline Total cholesterol (mg/dL) & $147.00 \pm 47.50$ & $150.81 \pm 34.25$ & .619 \\
\hline Triglyceride (mg/dL) & $115.86 \pm 65.05$ & $133.43 \pm 71.18$ & .195 \\
\hline $\mathrm{hs}-\mathrm{CRP}(\mathrm{mg} / \mathrm{dL})$ & $1.15 \pm 1.45$ & $2.88 \pm 6.02$ & .215 \\
\hline$E F(\%)$ & $50.17 \pm 19.01$ & $60.92 \pm 13.27$ & $<.001$ \\
\hline$E / E^{\prime}$ & $16.93 \pm 8.69$ & $14.03 \pm 5.97$ & .045 \\
\hline Stress (0-100) & $50.23 \pm 20.45$ & $40.33 \pm 21.93$ & .203 \\
\hline Self-management behaviour $(1-5)$ & $3.28 \pm 0.60$ & $3.54 \pm 0.56$ & .022 \\
\hline
\end{tabular}


Table 1 (continued)

QoL, quality of life; NYHA, New York Heart Association; HbA1C, hemoglobin A1c; HDL, high density lipoprotein; LDL, low density lipoprotein; hs-CRP, high sensitive $\mathrm{C}$-reactive protein; $\mathrm{EF}$, ejection fraction; E/E', early mitral inflow velocity/early diastolic mitral annular velocity

*Excluded, no response

Table 2 Factors associated with quality of life in participants with heart failure

\begin{tabular}{lllll}
\hline Variables & $\boldsymbol{B}$ & SE $(\boldsymbol{B})$ & $\boldsymbol{\beta}$ & $\boldsymbol{p}$ \\
\hline EF & 0.01 & 0.01 & 0.26 & .013 \\
E/E' & -0.01 & 0.01 & -0.04 & .665 \\
Self-management & 0.23 & 0.12 & 0.20 & .048 \\
behaviour & & & \\
Overall: $R^{2}=.14$, Adjusted $R^{2}=.11, F=5.03, p<.003$ & & \\
\hline
\end{tabular}

$\mathrm{EF}$, ejection fraction; $\mathrm{E} / \mathrm{E}^{\prime}$, early mitral inflow velocity/early diastolic mitral annular velocity

various physical, psychological, behavioural, and diagnostic test results, EF and self-management behaviour were factors that significantly associated with their QoL.

Previous studies have shown that EF is an important hallmark in people with HF that reflects the disease prognosis and outcomes, such as worsening symptoms, hospital readmission, mortality, and QoL $[9,20,21]$. Since HF cannot be ultimately cured, a necessary treatment strategy is to maintain the functional capacity and improve the QoL by continuous lifetime monitoring with the cooperation of healthcare providers and the individuals themselves $[10,22]$. Regular observation of the echocardiography results is essential to manage treatment goals in people with HF, as it is a simple and intuitive measurement for the evaluation of EF. Although increased EF can bring satisfaction to healthcare providers and people with HF, it is not easy to improve. Various medical treatments, such as pharmacological therapy, cardiac revascularization, resynchronization, and ventricular assist devices, have been availed of to improve the EF in people with HF; however, everyone does not get complete improvement with uniform treatment, so various studies are ongoing to determine the most favourable and optimal treatment $[23,24]$. In addition, measuring EF through echocardiography has also been reported to have limitations, such as limited reliability due to inter- and intra-observer variability and poor image quality $[25,26]$. Further, the concerns that QoL and the diverse symptoms of $\mathrm{HF}$ are not always associated with EF, which is a useful but simplistic parameter to assess the complexity of HF, should be considered in clinical practice [27].

Self-management behaviour can be a modifiable factor in improving QoL in people with HF. In the present study, self-management of the participants was one of the significant factors associated with their QoL. As we further noticed with the prediction model using the CART analysis that identified significant predictor variables and the splits, even in the low EF group, if the self-management behaviour score was relatively high, the relative QoL score was also high. It is in line with the results of a recent systematic review that showed evidence that people with HF can improve their QoL by promoting self-care behaviours [13]. Previous studies suggested that self-management interventions like education, support, and guidance can improve the QoL in people with HF using diverse delivery methods such as face-to-face interaction, telephonic conversation, accessing websites, mobile applications [28-31].

Self-management of HF is the individual's comprehensive behaviour, including maintaining self-care for physical and psychological stability and self-monitoring the possible worsening signs and symptoms [10]. Maintaining self-care includes taking prescribed medications, doing proper and regular physical activity, limiting salt and water uptake, keeping an adequate body weight, and so on. Self-monitoring also includes observing the signs and symptoms related to HF experienced by themselves and responding appropriately before advanced outcomes occur [10, 32]. For people with chronic conditions like HF, self-management

Table 3 Quality of life in participants with heart failure of each node based on CART

\begin{tabular}{|c|c|c|c|c|c|c|c|}
\hline Node & Definition & n (\%) & mean $\pm S D$ & $B$ & SE (B) & $\beta$ & $p$ \\
\hline Node 1 & $\mathrm{EF} \leq 36$ \& Self-Management $\leq 3.29$ & $6(5.0)$ & $2.70 \pm 0.25$ & & & & \\
\hline Node 2 & $\mathrm{EF} \leq 36$ \& Self-management $>3.29$ & $15(12.6)$ & $3.24 \pm 0.62$ & 0.54 & 0.30 & 0.26 & .043 \\
\hline Node 3 & $36<\mathrm{EF} \leq 69 \&$ Self-Management $\leq 4.04$ & $63(52.9)$ & $3.66 \pm 0.69$ & 0.97 & 0.27 & 0.69 & $<.001$ \\
\hline Node 4 & $36<\mathrm{EF} \leq 69$ \& Self-Management $>4.04$ & $10(8.4)$ & $4.09 \pm 0.39$ & 1.39 & 0.32 & 0.55 & $<.001$ \\
\hline Node 5 & $E F>69$ & $25(21.0)$ & $4.11 \pm 0.54$ & 1.42 & 0.28 & 0.82 & $<.001$ \\
\hline
\end{tabular}




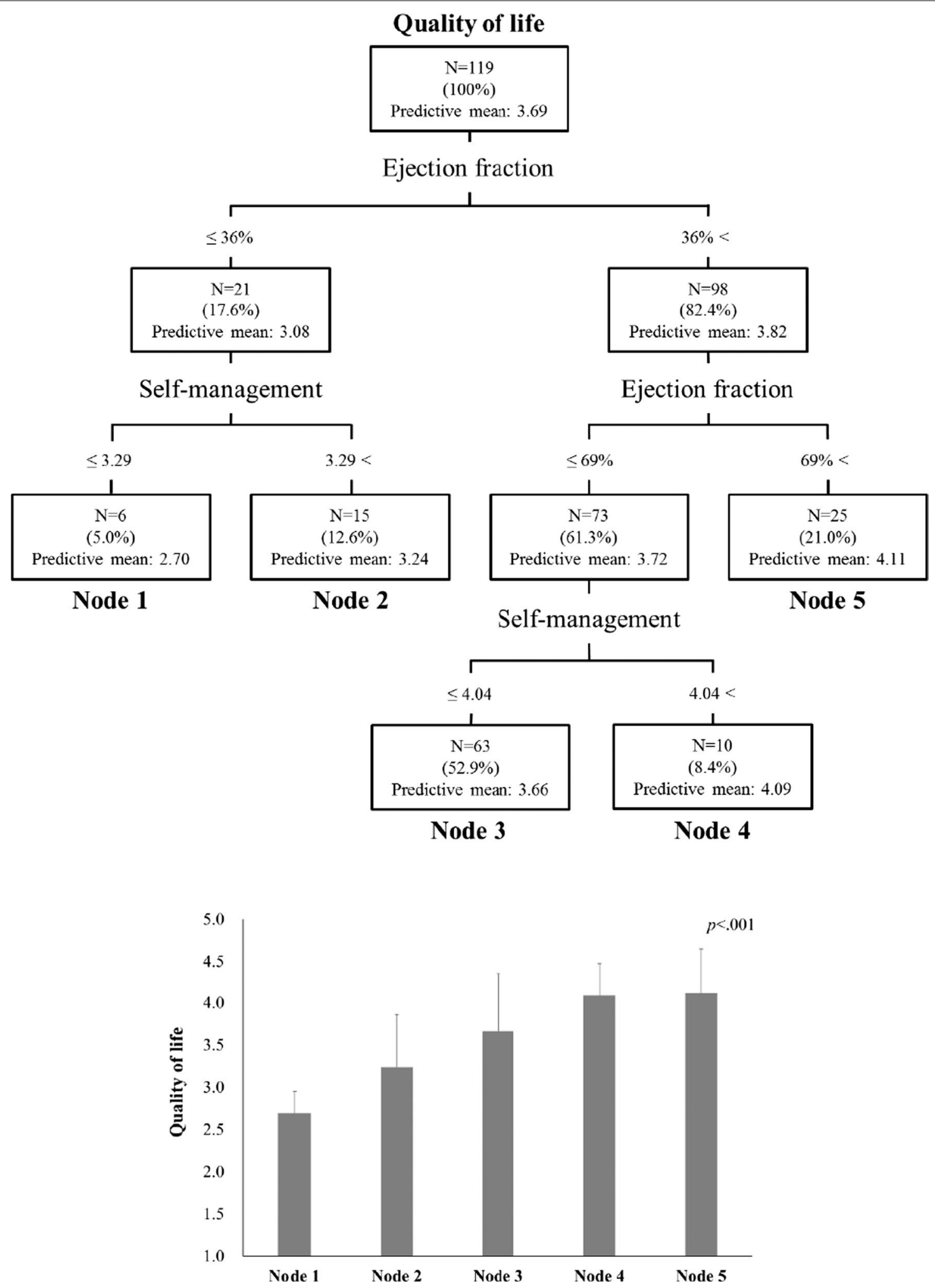

Fig. 1 Classification and regression tree for quality of life in participants with heart failure 
represents a critical strategy for improved treatment outcomes that they should accept as an aspect of daily routine for their lifetime rather than a short-term event [33]. Nevertheless, it is an ongoing challenge for healthcare providers and people with HF to enable self-management behaviour and continue to be stable without giving up. Some studies emphasised the role of people with HF in decision-making based on the knowledge and trial and error experience for self-management adherence [34-36]. Additionally, some studies highlighted the role of healthcare providers in improving self-management in people with $\mathrm{HF}$ through constant and multifaceted efforts, such as interactive education, teach-back, retraining, and support using diverse and customised delivery methods [28, 29,37]. Regardless of the initial low or high EF, efforts to improve the selfmanagement ability of people with HF will both promote their self-care and ultimately contribute to the achievement of the goal of treatment by enhancing the QoL.

This study has several limitations. First, this was a retrospective study based on a relatively small and convenient sample from two large tertiary medical centres in South Korea, and missing data existed in some variables, which may not represent the population and therefore has poor generalisability. Second, there may be differences in application to other participants since we analysed using the median value of the QoL. Third, we used the $E / E^{\prime}$ as a representative value for cardiac diastolic function in this study. However, diverse parameters, such as left atrial volume index, lateral early diastolic mitral annular velocity, the ratio of early diastolic transmitral flow velocity to late diastolic transmitral flow velocity (E/A), and E-wave deceleration time, can be considered for assessing diastolic function, and the assessment method we used is not applicable to certain populations with arrhythmia, mitral stenosis, mitral regurgitation, or mitral valve prosthesis [38]. In addition to the quantitative variables of $\mathrm{EF}$ and $\mathrm{E} / \mathrm{E}$, the qualitative variables of left ventricular systolic dysfunction and diastolic dysfunction should be considered. Lastly, we performed regression analyses with independent variables based on the significance only in the univariate analysis; however, sociodemographic characteristics should have been considered which may be confounding variables on the associations in the study. Future research should be expanded to include an increased number of participants and comprehensive variables and both quantitative and qualitative measurement tools to examine the validity of the prediction model using CART analysis presented in this study. Nevertheless, this study has strength in confirming that self-management is an important factor associated with the QoL in people with HF.

\section{Conclusions}

The EF and self-management behaviour are factors significantly associated with the QoL in people with HF. Furthermore, self-management behaviour should be considered as an important and modifiable factor that can increase QoL as a treatment goal of people with HF. Further ongoing research is needed to understand ways of effectively improving self-management adherence in people with HF.

\section{Abbreviations \\ CART: Classification and regression tree; E/A: Early diastolic transmitral flow velocity to late diastolic transmitral flow velocity; E/E': Early mitral inflow veloc- ity to early diastolic mitral septal annular velocity; EF: Ejection fraction; $\mathrm{HbA1C}$ : Hemoglobin A1C; HDL: High-density lipoprotein; HF: Heart failure; HRV: Heart rate variability; hs-CRP: High sensitivity C-reactive protein; LDL: Low-density lipoprotein; NYHA: New York Heart Association; QoL: Quality of life; WHOQOL- BREF: World Health Organization quality of life instrument short form.}

\section{Acknowledgements}

None.

\section{Authors' contributions}

Study conceptualization was performed by JAA. Data curation was performed by EYC, JSP and JAA. Formal analysis was performed by JAA, DM and HSL. Funding acquisition was performed by JAA. Supervision was performed by EYC, JSP and JAA. Writing was performed by JAA and DM. All authors read and approved the final manuscript.

\section{Funding}

This work was supported by the new faculty research fund in 2018 from Ajou University School of Medicine and the National Research Foundation of Korea (NRF) grant funded by the Korea government (MSIT) (No. NRF2019R1F1A1063148). This funding source had no role in study design, data collection, data analysis, data interpretation, or writing of the manuscript.

\section{Availability of data and materials}

The data that support the findings of this study are available from the authors upon reasonable request and with permission of the medical centres where the authors collected the data retrospectively.

\section{Declarations}

Ethics approval and consent to participate

The study was conducted with the approval of the Institutional Review Board (IRB) of Ajou University (IRB No. AJIRB-MED-SUR-19-349). As this study was a retrospective study, it was not possible to obtain direct consent from the subjects. Informed consent was waived, and the IRB approved the waiver. All methods were carried out in accordance with relevant guidelines and regulations.

\section{Consent for publication}

Not applicable.

\section{Competing interests}

All authors declare that they have no competing interests.

\section{Author details}

${ }^{1}$ Division of Cardiology, Gangnam Severance Hospital, Yonsei University College of Medicine, Seoul, Korea. ${ }^{2}$ Department of Cardiology, Ajou University School of Medicine, Suwon, Korea. ${ }^{3}$ Department of Nursing, College of Medicine, Wonkwang University, Iksan, Korea. ${ }^{4}$ Biostatistics Collaboration Unit, Department of Research Affairs, Yonsei University College of Medicine, Seoul, Korea. ${ }^{5}$ College of Nursing and Research Institute of Nursing Science, Ajou University, Worldcup-ro 164, Yeongtong-gu, Suwon 16499, Republic of Korea. 
Received: 21 April 2021 Accepted: 2 March 2022

Published online: 08 March 2022

\section{References}

1. American Heart Association. What is heart failure?. 2017. https:// www.heart.org/en/health-topics/heart-failure/what-is-heart-failure. Accessed 08 June 2020

2. Benjamin EJ, Muntner P, Alonso A, et al. Heart disease and stroke statistics - 2019 update: a report from the American Heart Association. Circulation. 2019;139:e56-528. https://doi.org/10.1161/CIR.0000000000 000659.

3. Ambrosy AP, Fonarow GC, Butler J, et al. The global health and economic burden of hospitalizations for heart failure. J Am Coll Cardiol. 2014;63:1123-33. https://doi.org/10.1016/j.jacc.2013.11.053.

4. Blecker S, Paul M, Taksler G, Ogedegbe G, Katz S. Heart failureassociated hospitalizations in the United States. J Am Coll Cardiol. 2013:61:1259-67. https://doi.org/10.1016/j.jacc.2012.12.038.

5. Lesyuk W, Kriza C, Kolominsky-Rabas P. Cost-of-illness studies in heart failure: a systematic review 2004-2016. BMC Cardiovasc Disord. 2018;18:Article 74. https://doi.org/10.1186/s12872-018-0815-3.

6. The Criteria Committee of the New York Heart Association. Functional capacity and objective assessment. In: Dolgin M, editror. Nomenclature and criteria for diagnosis of diseases of the heart and great vessels, 9th ed. Boston: Little Brown, and Company; 1994. p. 253-5.

7. Yancy CW, Jessup M, Bozkurt B, et al. 2017 ACC/AHA/HFSA focused update of the 2013 ACCF/AHA Guideline for the Management of Heart Failure. J Am Coll Cardiol. 2017;70:776-803. https://doi.org/10.1016/j. jacc.2017.04.025.

8. Severino P, Mather PJ, Pucci M, et al. Advanced heart failure and endstage heart failure: does a difference exist? Diagnostics (Basel). 2019; 9:Article 170. https://doi.org/10.3390/diagnostics9040170.

9. Alpert CM, Smith MA, Hummel SL, Hummel EK. Symptom burden in heart failure: assessment, impact on outcomes, and management. Heart Fail Rev. 2017;22:25-39. https://doi.org/10.1007/ s10741-016-9581-4.

10. Jaarsma T, Hill L, Bayes-Genis A, et al. Self-care of heart failure patients: practical management recommendations from the Heart Failure Association of the European Society of Cardiology. Eur J Heart Fail. 2021;23:157-74. https://doi.org/10.1002/ejhf.2008.

11. Riegel B, Jaarsma T, Strömberg A. A middle-range theory of self-care of chronic illness. Adv Nurs Sci. 2012;35:194-204. https://doi.org/10.1097/ ANS.0b013e318261b1ba.

12. Kępińska K, Adamczak DM, Kałużna-Oleksy M. Advanced heart failure: a review. Adv Clin Exp Med. 2019;28:1143-8. https://doi.org/10.17219/ acem/103669.

13. Sedlar N, Lainscak M, Mårtensson J, Strömberg A, Jaarsma T, Farkas J. Factors related to self-care behaviours in heart failure: a systematic review of European Heart Failure Self-Care Behaviour Scale studies. Eur J Cardiovasc Nurs. 2017;16:272-82. https://doi.org/10.1177/14745 15117691644

14. Ditewig JB, Blok H, Havers J, van Veenendaal H. Effectiveness of self-management interventions on mortality, hospital readmissions, chronic heart failure hospitalization rate and quality of life in patients with chronic heart failure: a systematic review. Patient Educ Couns. 2010;78:297-315. https://doi.org/10.1016/j.pec.2010.01.016.

15. Jaarsma T, Strömberg A, Mårtensson J, Dracup K. Development and testing of the European heart failure self-care behaviour scale. Eur J Heart Fail. 2003;5:363-70. https://doi.org/10.1016/S1388-9842(02) 00253-2.

16. The WHOQOL Group. Development of the World Health Organization WHOQOL-BREF Quality of Life Assessment. Psychol Med. 1998;28:5518. https://doi.org/10.1017/S0033291798006667.

17. Quiñones MA, Otto CM, Stoddard M, et al. Recommendations for quantification of Doppler echocardiography: a report from the Doppler Quantification Task Force of the Nomenclature and Standards Committee of the American Society of Echocardiography. J Am Soc Echocardiogr. 2002;15:167-84. https://doi.org/10.1067/mje.2002.120202.
18. Lemon SC, Roy J, Clark MA, Friedmann PD, Rakowski W. Classification and regression tree analysis in public health: methodological review and comparison with logistic regression. Ann Behav Med. 2003;26:17281. https://doi.org/10.1207/S15324796ABM2603_02.

19. Breiman L, Friedman J, Stone C, Olshen R. Classification and regression trees. London: Chapman and Hall; 2017.

20. Altaie $\mathrm{S}, \mathrm{K}$ halife $\mathrm{W}$. The prognosis of mid-range ejection fraction heart failure: a systematic review and meta-analysis. ESC Heart Fail. 2018:5:1008-16. https://doi.org/10.1002/ehf2.12353.

21. Chen X, Xin Y, Hu W, Zhao Y, Zhang Z, Zhou Y. Quality of life and outcomes in heart failure patients with ejection fractions in different ranges. PLOS ONE. 2019;14: e0218983. https://doi.org/10.1371/journal. pone.0218983.

22. Ponikowski P, Voors AA, Anker SD, et al. 2016 ESC guidelines for the diagnosis and treatment of acute and chronic heart failure: the task force for the diagnosis and treatment of acute and chronic heart failure of the European Society of Cardiology (ESC) developed with the special contribution of the heart failure association (HFA) of the ESC. Eur Heart J. 2016;37:2129-200. https://doi.org/10.1093/eurheartj/ehw128.

23. Basuray A, French B, Ky B, et al. Heart failure with recovered ejection fraction: linical description, biomarkers, and outcomes. Circulation. 2014;129:2380-7. https://doi.org/10.1161/CIRCULATIONAHA.113. 006855.

24. Basuray A, Fang JC. Heart failure with a better ejection fraction: why should we care? Circ Heart Fail. 2016;9: e003318. https://doi.org/10. 1161/CIRCHEARTFAILURE.116.003318.

25. Hsu JJ, Ziaeian B, Fonarow GC. Heart failure with mid-range (borderline) ejection fraction: clinical implications and future directions. J Am Coll Cardiol. 2017:5:763-71. https://doi.org/10.1016/j.jchf.2017.06.013.

26. Fedele F, Mancone M, Adamo F, Severino P. Heart failure with preserved, mid-range, and reduced ejection fraction: the misleading definition of the new guidelines. Cardiol Rev. 2017;25:4-5. https://doi. org/10.1097/CRD.0000000000000131.

27. Severino P, Maestrini V, Mariani MV, Birtolo LI, Scarpati R, Mancone M, Fedele F. Structural and myocardial dysfunction in heart failure beyond ejection fraction. Heart Fail Rev. 2020;25:9-17. https://doi.org/10.1007/ s10741-019-09828-8.

28. Abbasi A, Najafi Ghezeljeh T, Ashghali Farahani M. Effect of the selfmanagement education program on the quality of life in people with chronic heart failure: a randomized controlled trial. Electron Physician. 2018;10:7028-37. https://doi.org/10.19082/7028.

29. Abbasi A, Najafi Ghezeljeh $T$, Ashghali Farahani M, Naderi N. Effects of the self-management education program using the multi-method approach and multimedia on the quality of life of patients with chronic heart failure: a non-randomized controlled clinical trial. Contemp Nurse. 2018:54:409-20. https://doi.org/10.1080/10376178.2018.15387 05.

30. Buck HG, Stromberg A, Chung ML, et al. A systematic review of heart failure dyadic self-care interventions focusing on intervention components, contexts, and outcomes. Int J Nurs Stud. 2018;77:232-42. https://doi.org/10.1016/j.ijnurstu.2017.10.007.

31. Wali S, Demers $C$, Shah $H$, et al. Evaluation of heart failure apps to promote self-care: systematic app search. JMIR Mhealth Uhealth. 2019;7: e13173. https://doi.org/10.2196/13173.

32. Moser DK, Watkins JF. Conceptualizing self-care in heart failure: a life course model of patient characteristics. J Cardiovasc Nurs. 2008;23:205-18. https://doi.org/10.1097/01.JCN.0000305097.09710.a5.

33. Lorig KR, Holman HR. Self-management education: history, definition, outcomes, and mechanisms. Ann Behav Med. 2003;26:1-7. https://doi. org/10.1207/S15324796ABM2601_01.

34. Chen AM, Yehle KS, Albert NM, Ferraro KF, Mason HL, Murawski MM, Plake KS. Relationships between health literacy and heart failure knowledge, self-efficacy, and self-care adherence. Res Soc Adm Pharm. 2014;10:378-86. https://doi.org/10.1016/j.sapharm.2013.07.001.

35. Shao JH, Chang AM, Edwards H, Shyu YIL, Chen SH. A randomized controlled trial of self-management programme improves health-related outcomes of older people with heart failure. J Adv Nurs. 2013;69:245869. https://doi.org/10.1111/jan.12121.

36. Son CS, Kim YN, Kim HS, Park HS, Kim MS. Decision-making model for early diagnosis of congestive heart failure using rough set and decision 
tree approaches. J Biomed Inform. 2012;45:999-1008. https://doi.org/ 10.1016/j.jbi.2012.04.013.

37. Dinh HT, Bonner A, Ramsbotham J, Clark R. Cluster randomized controlled trial testing the effectiveness of a self-management intervention using the teach-back method for people with heart failure. Nurs Health Sci. 2019;21:436-44. https://doi.org/10.1111/nhs.12616.

38. Mitter SS, Shah SJ, Thomas JD. A test in context: E/A and E/e' to assess diastolic dysfunction and LV filling pressure. J Am Coll Cardiol. 2017;69:1451-64. https://doi.org/10.1016/j.jacc.2016.12.037.

\section{Publisher's Note}

Springer Nature remains neutral with regard to jurisdictional claims in published maps and institutional affiliations.

- fast, convenient online submission

- thorough peer review by experienced researchers in your field

- rapid publication on acceptance

- support for research data, including large and complex data types

- gold Open Access which fosters wider collaboration and increased citations

- maximum visibility for your research: over $100 \mathrm{M}$ website views per year

At BMC, research is always in progress.

Learn more biomedcentral.com/submissions 